Provided for non-commercial research and education use. Not for reproduction, distribution or commercial use.

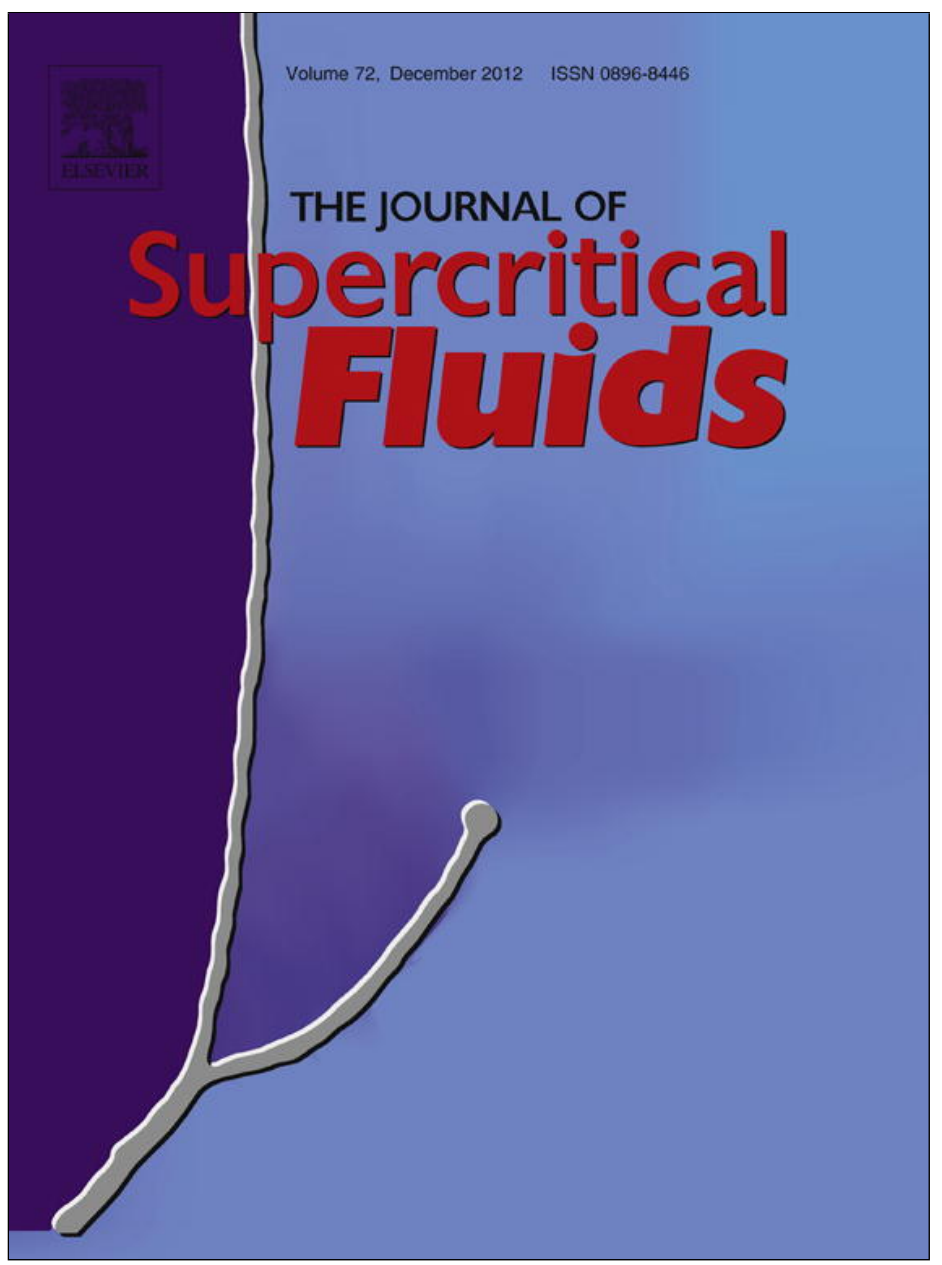

This article appeared in a journal published by Elsevier. The attached copy is furnished to the author for internal non-commercial research and education use, including for instruction at the authors institution and sharing with colleagues.

Other uses, including reproduction and distribution, or selling or licensing copies, or posting to personal, institutional or third party websites are prohibited.

In most cases authors are permitted to post their version of the article (e.g. in Word or Tex form) to their personal website or institutional repository. Authors requiring further information regarding Elsevier's archiving and manuscript policies are encouraged to visit:

http://www.elsevier.com/copyright 


\title{
The role of organic solvent on the preparation of chitosan scaffolds by supercritical assisted phase inversion
}

\author{
Ana Rita C. Duarte ${ }^{a, b}, *$, João F. Mano ${ }^{a, b}$, Rui L. Reis ${ }^{a, b}$ \\ a 3B's Research Group - Biomaterials, Biodegradables and Biomimetics, University of Minho, Headquarters of the European Institute of \\ Excellence on Tissue Engineering and Regenerative Medicine, AvePark, 4806-909 Taipas, Guimarães, Portugal \\ ${ }^{\mathrm{b}}$ IBB - Institute for Biotechnology and Bioengineering, PT Government Associated Laboratory, Guimarães, Portugal
}

\section{A R T I C L E I N F O}

\section{Article history:}

Received 8 June 2009

Received in revised form 2 December 2010 Accepted 3 December 2010

\section{Keywords:}

Chitosan

Supercritical fluids

Solubility parameter

Flory-Huggins interaction parameter

Scaffolds

Tissue engineering

\begin{abstract}
A B S T R A C T
The aim of this study was to evaluate the possibility of preparing chitosan porous matrixes using supercritical fluid technology. Supercritical immersion precipitation technique was used to prepare scaffolds of a natural biocompatible polymer, chitosan for tissue engineering purposes. The physicochemical and biological properties of chitosan make it an excellent material for the preparation of drug delivery systems and for the development of new biomedical applications in many fields from skin to bone or cartilage.

Supercritical assisted phase inversion experiments were carried out and the effect of different organic solvents on the morphology of the scaffolds was assessed. Chitosan scaffold morphology, porosity and pore size were evaluated by SEM and micro-CT. A thermodynamic analysis of the process was carried out and insights on the solubility parameter and Flory-Huggins interaction parameters are given. The preparation of a highly porous and interconnected structure of a natural material, chitosan, using a clean and environmentally friendly technology constitutes a new processing technology for the preparation of scaffolds for tissue engineering using these materials.
\end{abstract}

(c) 2011 Elsevier B.V. All rights reserved.

\section{Introduction}

Chitin is widely found in shells of crustaceous such as crabs and shrimp and it is the second most abundant polymer after cellulose. Chitin forms strong inter- and intramolecular hydrogen bonds, which are difficult to break. Therefore its solubility in common solvents is rather constrained. For this reason, limited utilization of this natural resource has been reported. Up to date, the majority of uses of chitin are mainly related to chitosan, which is a cationic polymer derived from chitin comprising copolymers of $\beta(1 \rightarrow 4)$-glucosamine and N-acetyl-d-glucosamine. The physicochemical and biological properties of chitosan make it an excellent material for the preparation of drug delivery systems and for the development of new biomedical applications in many fields from skin to bone or cartilage [1,2].

Chitosan has been processed in different forms to be used in tissue engineering applications, namely, membranes [3], particles [4], fibers and 3D fiber meshes [4,5]. The use of chitosan as a drug delivery vehicle has also been reported in different studies [6,7]. In tissue

\footnotetext{
* Corresponding author at: 3B's Research Group - Biomaterials, Biodegradables and Biomimetics, University of Minho, Headquarters of the European Institute of Excellence on Tissue Engineering and Regenerative Medicine, AvePark, 4806-909 Taipas, Guimarães, Portugal. Fax: +351253510 909.

E-mail address: aduarte@dep.uminho.pt (A.R.C. Duarte).
}

engineering applications, chitosan sponges have been described as deliver systems able to carry active agents or biomolecules and growth factor $[8,9]$. The preparation of these systems normally involves freeze-drying or lyophilizing a chitosan gel solution using diluted acetic acid solutions $[10,11]$.

One of the most important stages of tissue engineering is the design and processing of a porous 3D structure, with high porosity, high interconnectivity between the porous and uniform distribution. A variety of processing techniques have been developed and include solvent casting and particles leaching, compression moulding and particle leaching, thermally induced phase separation, gas-foaming processes, among others [12]. The main disadvantages of these methods are the use of organic solvents and the high temperatures required. The presence of residual organic solvents is being rigorously controlled by international safety regulations, thus it is necessary to warrant the complete removal and absence of these substances. Supercritical fluid technology appears to be, therefore an interesting alternative to the traditional processing methods [13-15].

The phase inversion technique involves casting of a polymer solution onto an inert support followed by immersion of the support with the cast film into a bath filled with a non-solvent for the polymer. The contact between the solvent and the non-solvent causes the solution to be phase-separated. If the non-solvent used is a supercritical fluid this adds several advantages to the process. One of the most important advantages of the use of carbon dioxide 


Formic acid Acetic acid

Scheme 1. Molecular structure of the solvents used in this work.

is the fact that simply by tuning the process conditions, i.e. pressure and temperature, one can tailor the final structure of the product. Additionally, when carbon dioxide is used as a non-solvent a subsequent drying step is avoided and the porous structure obtained is a dry product free of any residual solvent.

The use of carbon dioxide as a non-solvent for phase separation has been successfully reported in the literature for example for PLLA [16,17], PMMA [18], Nylon 6 [19], PS [20], cellulose acetate $[21,22]$, polysulfone $[23,24]$ and polycarbonate/PEG [25]. Recently, it has been reported the use of supercritical fluid assisted phase inversion method for processing natural based polymers, namely, a polymeric blend of starch and poly-L-lactic acid from a chloroform solution was processed [26]. Temtem and co-workers reported the precipitation of chitosan membranes from an aqueous solution of dilute acetic acid [27]. Nonetheless, the presence of water and its poor solubility in the supercritical phase make the proposed process time consuming and energy intensive. The feasibility of processing chitosan from organic solutions was evaluated in this work. Although organic solvents are used, the use of supercritical carbon dioxide $\left(\mathrm{scCO}_{2}\right)$ allow complete solvent removal as $\mathrm{CO}_{2}$ has good diffusivity and mass transfer properties. The ability of carbon dioxide to diffuse and penetrate in the bulk of the 3D matrix grantees the complete extraction of the organic solvent [28].

The possibility of dissolution of this natural polymer in carboxylic acids, such as formic acid (FA) and acetic acid (AA) [29] and in 1,1,1,3,3,3-hexa-fluoro-2-propanol (HFIP) [30] has been described in previous works; the molecular structure of the solvents is presented in Scheme 1. Such studies provided good indications that one could use such substances to process porous chitosan-based structures by combining them with $\mathrm{scCO}_{2}$.

The role of the organic solvent on the morphology of the scaffolds obtained was studied and it was explained regarding the Hildebrand solubility parameter and the Flory-Huggins solution theory.

\section{Materials and methods}

\subsection{Supercritical assisted phase-inversion process}

The phase inversion experiments were carried out in an apparatus especially for this purpose and described elsewhere [26].

Briefly, in each experiment a small amount (ca. $2 \mathrm{ml}$ ) of the chitosan solution ( $2 \mathrm{wt} \%$ ) is loaded in a stainless steel cap with $2 \mathrm{~cm}$ diameter, which is placed inside the high pressure vessel. The vessel is heated in by means of an electric thin band heater connected to a temperature controller, that maintains temperature within $\pm 1 \mathrm{~K}$. Carbon dioxide is pumped into the vessel using high pressure piston pump (P-200A Thar Technologies) until the operational pressure is attained. The pressure inside the vessel is measured with a pressure transducer. The system was closed for $45 \mathrm{~min}$ to allow the occurrence of phase separation. Afterwards the system is flushed for another $45 \mathrm{~min}$, with a stream of carbon dioxide at very low flow rate $(5 \mathrm{~g} / \mathrm{min})$, in order to ensure complete drying of the scaffolds. The flow is regulated by a flow meter (Siemens, SITRANS FC MASS FLO MASS2100).

\subsection{Scaffold characterization}

Scanning electron microscopy - SEM: Samples of the scaffolds prepared were observed by a Leica Cambridge S360 Scanning Electron Microscope. The films were fixed by mutual conductive adhesive tape on aluminium stubs and covered with gold palladium using a sputter coater.

Micro-computed tomography - $\mu$-CT: The inner structure, porosity and interconnectivity were evaluated by microcomputerized tomography using a Scanco 20 equipment (Scanco Medicals, Switzerland) with penetrative X-rays of $40 \mathrm{keV}$. The Xray scans were acquired in high-resolution mode $(39.39 \mu \mathrm{m})$. CT Analyser $^{\circledR}$ (SkyScan, Belgium) was used to visualize the 2D X-ray sections images of the scaffolds.

\section{Results and discussion}

In this work, the possibility of preparing chitosan scaffolds for tissue engineering applications using supercritical assisted phase inversion technique was evaluated. The solubility of chitosan in different organic solvents has been reported in literature, more specifically chitosan is soluble in carboxylic acids, such as formic or acetic acid and it has also been reported to be soluble in HFIP. The importance of this study relies on the implications of the selection of a proper combination of non-solvent/solvent/polymer for the success of the phase inversion process. Table 1 presents some physical properties of the solvents and non-solvent used.

In order to be able to compare the structures obtained the scaffolds were processed at the same operating conditions, $333.15 \mathrm{~K}$, 15.0 MPa from a solution with $2 \mathrm{wt} \%$.

In this study the concentration was kept constant in order to evaluate the sole effect of the solvent on the morphology of the structures obtained. However, it has been reported in the literature an increase in polymer concentration will increase the thickness of the top layer and decrease the pore size [31].

Fig. 1 represents the SEM images of the cross section of the scaffolds obtained and a representative $2 \mathrm{D}$ image of a slice of the material.

From these images it is noticeable the strong dependence of the structure obtained with the solvent used. When chitosan was precipitated from HFIP or acetic acid solution a 3D structure was obtained. However, the scaffolds obtained from HFIP solution presented an upper compact layer, which was not observed in chitosan

Table 1

Physical properties of the substances used for the processing of chitosan.

\begin{tabular}{|c|c|c|c|c|}
\hline & \multicolumn{3}{|l|}{ Solvent } & \multirow{2}{*}{$\begin{array}{l}\text { Non-solvent } \\
\text { Carbon dioxide }\end{array}$} \\
\hline & Formic acid ${ }^{\mathrm{a}}$ & Acetic acid ${ }^{\mathrm{a}}$ & HFIPb & \\
\hline $\mathrm{Mw}(\mathrm{g} / \mathrm{mol})$ & 46 & 60 & 168 & 48 \\
\hline $\mathrm{Bp}(\mathrm{K})$ & 363.32 & 390.87 & 349.14 & 297.37 \\
\hline$T_{\mathrm{c}}(\mathrm{K})$ & 580.05 & 592.75 & 468.45 & 304.25 \\
\hline$p_{\mathrm{c}}(\mathrm{MPa})$ & 7.39 & 5.78 & 3.42 & 7.39 \\
\hline Acentric factor $\omega$ & 0.473 & 0.4624 & & 0.225 \\
\hline
\end{tabular}

a $[31]$

b $[32]$. 


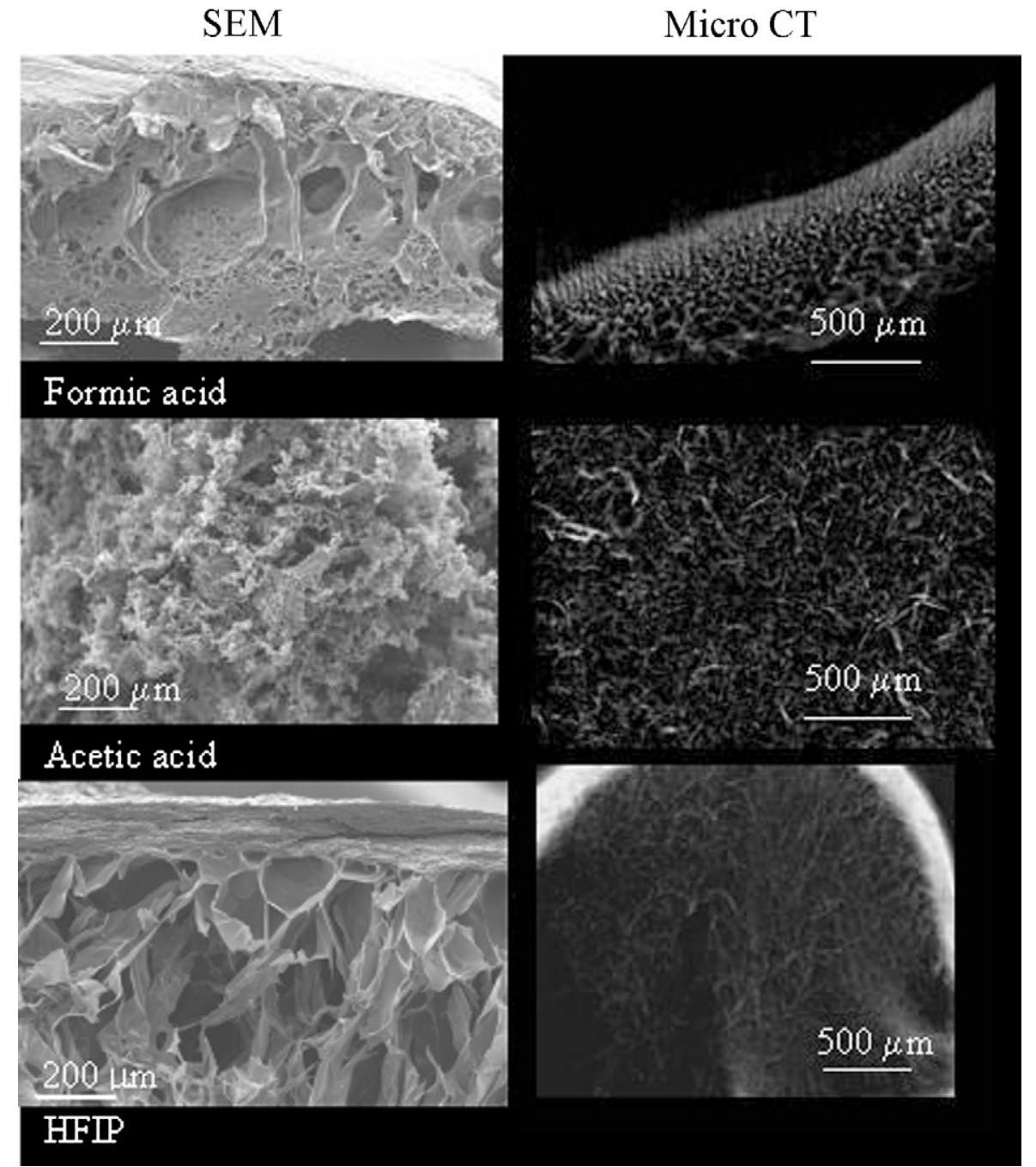

Fig. 1. SEM images and 2D micro CT representation of the scaffolds prepared from different organic solutions at $333.15 \mathrm{~K}$ and $15.0 \mathrm{MPa}$.

scaffolds precipitated from acetic acid. Furthermore, chitosan processed from an acetic acid solution presented a more homogeneous structure. On the other hand, when a formic acid solution was processed a thin membrane was obtained.

The formation of a compact layer on the scaffolds prepared from HFIP solution is related to the low boiling point of the organic solvent. As this is close to the operating temperature, after loading the mould with the polymer solution it is placed inside the highpressure vessel, which is at $333.15 \mathrm{~K}$ (the operating temperature) and only then the system is pressurized. During this procedure a certain amount of organic solvent evaporates and a polymer concentration gradient is formed leading to the formation of a compact layer on top of the polymeric matrix.

Micro CT allows us a more qualitative interpretation of the morphology of the scaffolds. From the analysis of the 2D slices and the reconstruction of the 3D structure it is possible to assess parameters such as, porosity, average pore size and pore size distribution. Table 2 summarizes the experiments performed and the results obtained, in terms of porosity and average pore size. In Fig. 2 the pore size distribution on the three scaffolds prepared is presented.

As it can be observed, not only the pores are larger when chitosan was precipitated from formic acid or HFIP but also there is a large size distribution, implying the production of a heterogeneous matrix. Such results demonstrate that completely different morphologies are obtained from the precipitation with different solvents. 3D models of the scaffolds produced were constructed and
Table 2

Summary of the experiments performed and the characteristics of the porous structures obtained by $\mu$-CT.

\begin{tabular}{llllc}
\hline Experiment \# & Solvent & $\begin{array}{l}\text { Chitosan } \\
\text { concentration } \\
(\text { wt\%) }\end{array}$ & Porosity (\%) & $\begin{array}{l}\text { Average pore } \\
\text { size }(\mu \mathrm{m})\end{array}$ \\
\hline 1 & Formic acid & $2 \%$ & 29 & 62 \\
2 & Acetic acid & $2 \%$ & 47 & 110 \\
3 & HFIP & $2 \%$ & 90 & 600 \\
\hline
\end{tabular}

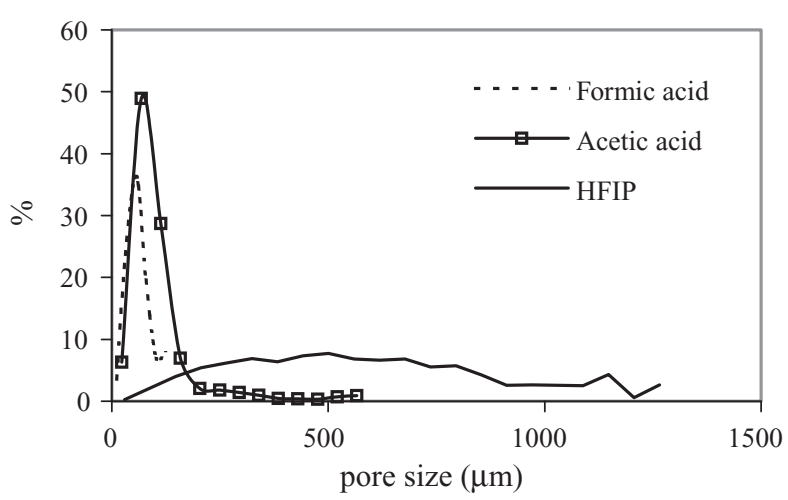

Fig. 2. Pore size distribution of chitosan scaffolds precipitated from different organic solutions. 


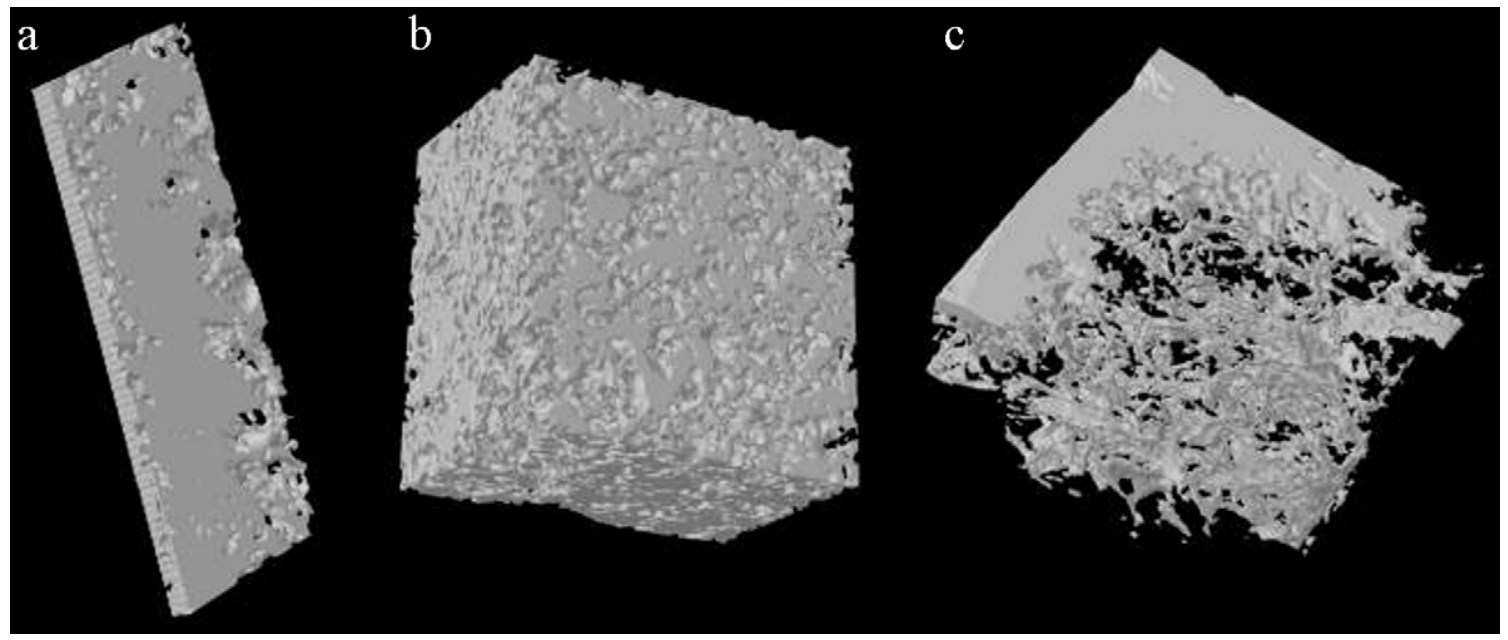

Fig. 3. 3D model of chitosan scaffolds precipitated from different organic solutions: (a) formic acid; (b) acetic acid; (c) HFIP.

the differences among them are highlighted. Fig. 3 represents the 3D models of chitosan scaffolds obtained for the different solvents.

\subsection{Ternary phase behaviour systems: \\ polymer-solvent-antisolvent, an equilateral triangle?}

The supercritical assisted phase inversion process relies on two mechanisms that take place simultaneously, namely the diffusion of carbon dioxide into the polymer solution and the extraction of the organic solvent by the supercritical fluid. The choice of the best solvent involves many times several factors which will have an effect on the ability of the solvent to adequately dissolve the material. The Hildebrand solubility parameter is one of the most widely applicable solubility scale, which reflects the total Van der Waals forces between molecules. The solubility parameter is, therefore, an important parameter, which is a function of the cohesive energy density. There are several methods to estimate this parameter. A semi-empirical Eq. (1) described by Giddings et al. [32] to calculate the solubility parameter was used, as this can be easily calculated based on the fluid properties, giving an indicative value of the solvent power of the compressed fluid:

$\delta=1.25 p_{c}{ }^{1 / 2}\left[\frac{\rho_{r}}{\rho_{r(\text { liq })}}\right]$

where $\delta$ is the solubility parameter, $p_{c}$ is the critical pressure of the fluid phase, $\rho_{r}$ is the reduced density of the fluid phase and $\rho_{r}$ (liq) is the reduced density of the fluid in the liquid state which is typically considered to be 2.66 for carbon dioxide [34]. The calculation of the reduced density of the fluid phase was performed using the Phase-Equilibria (PE) program [35].

Vapour-liquid equilibrium (VLE) measurements for the binary systems carbon dioxide + carboxylic acid are reported in the literature. Important to this work are the phase equilibria data of carbon dioxide + formic acid and carbon dioxide + acetic acid, reported by McHugh and co-workers [33]. Regarding the binary system carbon dioxide + HFIP, VLE data are not available in the literature. For this reason, and to avoid large calculation errors, solubility parameter for this system was not calculated.

In order to determine the density of the fluid phase, estimation of binary interaction parameters (Table 3) and modeling of VLE data was required. The Peng-Robinson equation of state (PR-EOS) was chosen to model the system [36]:

$P=\frac{R T}{v-b}-\frac{a(T)}{v^{2}+2 b v-b^{2}}$
Table 3

Binary interaction parameters used in PR-EOS.

\begin{tabular}{lcc}
\hline & $k_{i j}$ & $l_{i j}$ \\
\hline $\mathrm{CO}_{2}+$ formic acid & -0.015 & -0.132 \\
$\mathrm{CO}_{2}+$ acetic acid & 0.101 & 0.04
\end{tabular}

The mixture parameters $a$ and $b$ can be regarded as a measure of the intermolecular attraction force and the size of the hard spheres, respectively and can be defined by the following quadratic mixing rules:

$a=\sum_{i} \sum_{j} x_{i} x_{j} a_{i j}$

$a_{i j}=\sqrt{a_{i} a_{j}}\left(1-k_{i j}\right)$

$b=\sum_{i} \sum_{j} x_{i} x_{j} b_{i j}$

$b_{i j}=\frac{b_{i}+b_{j}}{2}\left(1-l_{i j}\right)$

where $k_{i j}$ and $l_{i j}$ are interaction binary parameters that are determined by the fitting of pressure-composition data and $a_{i j}$ and $b_{i j}$ are the pure component parameters defined by Peng and Robinson [36].

The good correlation between VLE experimental data and modeling of the pressure-composition trend using the PR-EOS is evidenced in Fig. 4 for the system carbon dioxide + acetic acid.

The solubility parameter of the fluid phase was calculated to be $11.88 \mathrm{MPa}^{1 / 2}$ for the system carbon dioxide + formic acid and

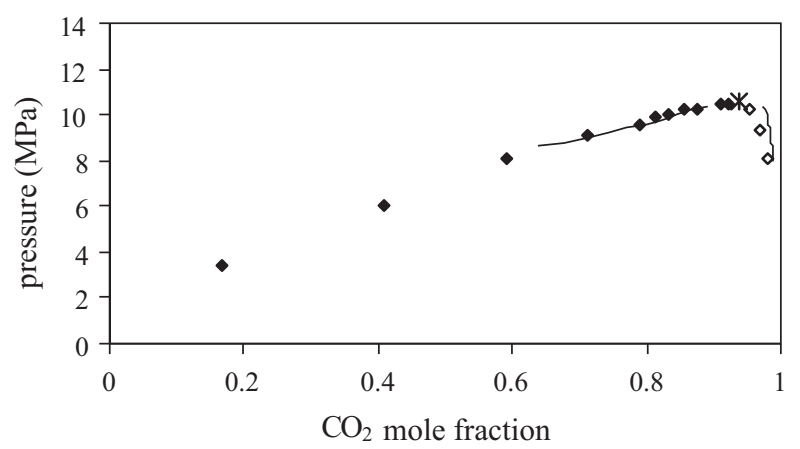

Fig. 4. Phase equilibria data for the system acetic acid + carbon dioxide: close symbols - bubble points; open symbols - dew points; * critical point of the mixture; line corresponds to the modeling. 
Table 4

Solubility parameters of the pure compounds and binary systems.

\begin{tabular}{|c|c|c|c|c|}
\hline & \multicolumn{3}{|l|}{$\delta\left(\mathrm{MPa}^{1 / 2}\right)$} & \multirow[t]{2}{*}{$\left(\delta_{1}-\delta_{2}\right)^{2}(\mathrm{MPa})$} \\
\hline & Pure components ${ }^{\mathrm{a}}$ & Pure components at experimental conditions & Binary system solvent/non-solvent & \\
\hline Formic acid & $24.9^{\mathrm{b}}$ & 19.04 & 11.88 & 129.9 \\
\hline Acetic acid & $21.4^{\mathrm{b}}$ & 20.58 & 10.88 & 62.4 \\
\hline HFIP & $19.3^{c}$ & - & - & 33.6 \\
\hline Carbon dioxide & $13.5^{\mathrm{d}}$ & 4.59 & & - \\
\hline Chitosan & $43.06^{\mathrm{e}}$ & & & - \\
\hline $\begin{array}{l}\text { a At } 298.15 \mathrm{~K} . \\
\text { b }[37] . \\
\text { c }[38] . \\
\text { d } 24 \text { value at } 30 \\
\text { e }[39] .\end{array}$ & nd $13 \mathrm{MPa}$. & & & \\
\hline
\end{tabular}

$10.88 \mathrm{MPa}^{1 / 2}$ for the system carbon dioxide + acetic acid. Table 4 summarizes the solubility parameters for the pure components at $298.15 \mathrm{~K}$ and $0.1 \mathrm{MPa}$, and at the operating conditions and for the binary systems solvent/non-solvent. Matsuyama and co-workers have interpreted the morphology of materials processed by the supercritical assisted phase inversion process, through the evaluation of the square of solubility parameter difference between non-solvent and solvent, $\left(\delta_{1}-\delta_{2}\right)^{2}$ at ambient conditions [22]. The numbered subscripts 1,2 and 3 correspond to non-solvent, solvent and polymer, respectively.

The difference between the solubility parameters is a measure of the mutual affinity of the solvent/non-solvent. As this difference increases, the affinity between organic solvent and carbon dioxide decreases.

Fig. 5 represents the trend of the porosity and pore size distribution as a function of solvent affinity.

The high solubility between the organic solvent and the antisolvent will favour the phase inversion process because a higher affinity of the solvent to the carbon dioxide will cause the phase separation and the precipitation of the polymer with a porous structure. Lower solvent affinity, i.e., higher square solubility parameter difference, will result in a decrease in the porosity and pore size of the scaffolds.

The results obtained are different from what is reported in the literature, however due to the nature of the systems studied and the conditions in which the experiments were performed it is not possible to make a straightforward comparison between what is reported in Refs. [22-24] and the taken conclusions. Major differences arise from the fact we are producing a 3D matrix from chitosan, a semicrystalline polymer that can potentially crystallize during the phase inversion, which may increase the complexity of the process.

The complexity of the mechanisms involved in the process is associated with the interactions between the components of the

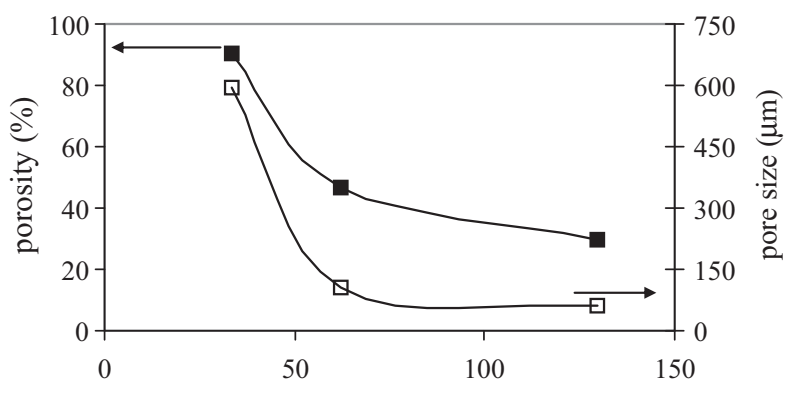

square of solubility parameter difference

Fig. 5. Effect of square solubility parameter difference on the scaffold porosity and pore size ( $\square)$. ternary mixture, i.e., polymer-solvent, polymer-non-solvent and solvent-non-solvent interactions [40].

A better understanding of the mechanisms involved in the process requires the knowledge of the ternary phase diagram of the components in the system.

The boundary between the homogeneous phase and the liquid-liquid (L-L) demixing gap is often called binodal and it corresponds to the cloud point curve of the polymer. Usually the region of $\mathrm{L}-\mathrm{L}$ demixing is subdivided into a region of spinodal demixing. The area in between corresponds to two different metastable regions where nucleation and growth take place.

According to the theory of Flory-Huggins the size and location of the demixing gap, as well of the critical point, depends on the molar volumes of the components present in the system and their interactions $[1,41]$. Flory-Huggins interaction parameter is commonly used to measure the polymer/solvent compatibility. Nonetheless it can also be used to evaluate the compatibility between solvent/nonsolvent and polymer/nonsolvent. Interaction parameters $\left(\chi_{i, j}\right)$ can be calculated based on Eq. (2):

$\chi_{i, j}=V_{m i} \frac{\left(\delta_{i}-\delta_{j}\right)^{2}}{R T}$

where $V_{m}$ is the molar volume, $R$ is the universal gas constant and $T$ is temperature. For our ternary system $\chi_{1,2}$ corresponds to the interaction parameter between non-solvent/solvent, $\chi_{1,3}$ is the interaction parameter between non-solvent/polymer and $\chi_{2,3}$ the interaction parameter solvent/polymer.

We can estimate the following inequalities, for the FloryHuggins interaction parameters, between non-solvent-solvent and solvent-polymer, based on the solubility parameters (Table 4): $\chi_{1,2}$ FA $>\chi_{1,2}$ AA $>\chi_{1,2}$ HFIP and $\chi_{2,3}$ FA $<\chi_{2,3}$ AA $<\chi_{2,3}$ HFIP.

The influence of these parameters has been summarized in a review paper by Feijen and co-workers [42]. In a first approximation differences in molar volumes are negligible compared to the influence of the interaction parameters. Regarding the Flory-Huggins parameter, $\chi_{1,3}$ determines not only the surface area of the demixing gap, but also the point of intersection of the demixing gap with the polymer/non-solvent axis. When $\chi_{1,3}$ is high this intersection is located at very high polymer concentrations. On the other hand, high $\chi_{2,3}$ values indicate low mutual affinity between the organic solvent and the polymer, which consequently leads to an increase in the demixing gap. The affinity between solvent/non-solvent, quantified by the term $\chi_{1,2}$ is directly proportional to the magnitude of the gap. Therefore, low interaction parameters strongly increase the demixing gap. From these assumptions we can predict the ternary phase diagram for all the three solvents studied (Fig. 6).

The formation mechanisms that govern the morphology of the membranes, namely pore size and porosity involve both equilibrium thermodynamics and kinetics $[43,44]$. The equilibrium 


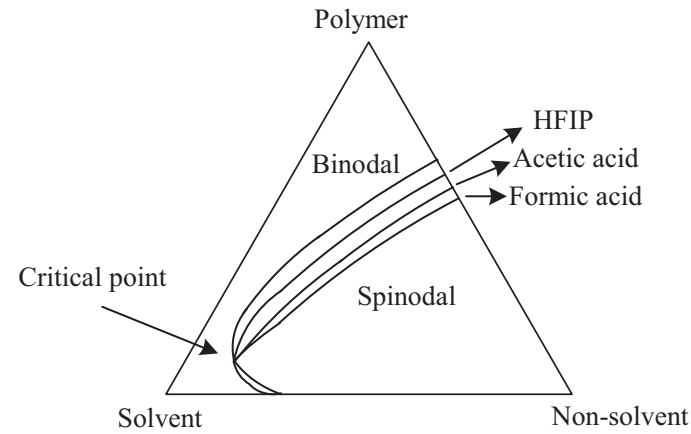

Fig. 6. Schematic representation of the ternary phase diagram of the components involved in the phase inversion process.

phase diagram represents the thermodynamically favoured processes that might occur during phase separation, nonetheless it is the kinetics that will determine to what extent the thermodynamically favoured phase transition will take place. Furthermore, non-equilibrium processes may play an important role during the membrane formation. The morphology of the matrixes prepared can be characterized as cellular structures, nodules, bicontinuous structures, unconnected particles or macrovoids [45].

The majority of the matrixes are prepared by controlled phase separation of polymer solutions in two phases: one with a high polymer concentration and one with a low polymer concentration. A proposed mechanism of membranes formation indicates that a porous cellular structure is obtained if $\mathrm{L}-\mathrm{L}$ demixing occurs by nucleation and growth of the droplets of a polymer lean phase [26].

The correlation between theory and matrix morphology can also be based on mass transfer models. Reuvers and co-workers [46-48] demonstrated that the mass transfer processes associated with porous development in scaffolds can be divided into delayed demixing and instantaneous demixing. The delay period is the time in which the composition of the mixture remains the same and it represents one of the most important parameters in the theory of phase inversion processes. During the process, the non-solvent concentration in the polymer solution gradually increases until the demixing gap is entered. A larger metastable region, i.e. a larger demixing gap, is associated to a higher delay time. In addition, a qualitative generalized interpretation indicated that by increasing the interaction parameter between solvent/non-solvent $\chi_{1,2}$, i.e., when the mutual affinity between solvent and non-solvent decreases, an increase in the delay time will be observed [42]. This can help us to understand the chitosan structures obtained in this work. The precipitation from a formic acid solution lead to a dense matrix with low porosity, indicating that a scaffold with close pore structure has been formed. On the other hand, scaffolds produced from HFIP solution presented macrovoids, which correspond to very elongated pores over the entire thickness of the scaffolds. Macrovoids are usually related with instantaneous demixing, therefore, low $\chi_{1,2}$. The mutual affinity of HFIP and carbon dioxide is the greatest among the three solvents tested, as it could be confirmed by the square difference of the Hildebrand solubility parameters and by the smaller demixing gap in the ternary phase diagram. For this reason, there is a rapid diffusion of carbon dioxide into the polymeric solution and rapid precipitation occurs. The appearance of a dense layer on top of the matrix is also an indication of the fast precipitation mechanism.

Regarding the precipitation from an acetic acid solution it falls in between these two categories. In this case a bicontinuous structure was obtained. This system is characterized by a homogeneous pore size distribution with pores presenting an average size of $\sim 100 \mu \mathrm{m}$, in addition surfaces appear very rough which can enhance the transport properties within the structure and could also encourage cell attachment and proliferation, when aiming tissue engineering applications. These matrixes are also characterized by a highly interconnected porous structure. Having in mind the particular application of tissue engineering and the fact that ideal scaffolds for bone tissue engineering require three-dimensionally interconnected porous structures, so nutrients and oxygen can be accessible to the cells together with the elimination of cell wastes, chitosan structures prepared from acetic acid solutions by supercritical assisted phase inversion are potential candidates for this purpose.

\section{Conclusions}

Supercritical fluid assisted phase inversion process was used to prepare chitosan scaffolds from organic solutions. The role of the organic solvent on the morphology of the matrixes obtained was discussed only a few times in the literature, when phase inversion technique is used. In this work we present some thermodynamics insights on the importance of the selection of the most appropriate non-solvent/solvent/polymer systems in order to be able to produce a material with the desired characteristics. In tissue engineering the preparation of a 3D matrix, highly porous and interconnected is crucial for the success of the implant. From three different organic solutions (formic acid, acetic acid and HFIP) we prepared very different materials, namely a dense chitosan membrane from formic acid, a macrovoid structure, with a dense layer on top from HFIP solution and a homogeneous scaffold with potential for tissue engineering applications from an acetic acid solution. The knowledge of solubility parameter and the interaction coefficients non-solvent/solvent, non-solvent/polymer and solvent/polymer help understanding the morphology of the scaffolds.

\section{Acknowledgements}

Ana Rita C. Duarte is grateful for financial support from Fundação para a Ciência e Tecnologia (FCT) through the grant SFRH/BPD/34994/2007. The support through the FCT project PTDC/QUI/68804/2006 is also acknowledged.

\section{References}

[1] J.F. Mano, G.A Silva, H.S Azevedo, P.B. Malafaya, R.A Sousa, S.S Silva, LF. Boesel, J.M. Oliveira, T.C. Santos, A.P.N. Marques, M. Neves, R.L. Reis, Natural origin biodegradable systems in tissue engineering and regenerative medicine: present status and some moving trends, J. Royal Society Interface 4 (17) (2007) 999-1030.

[2] N.M. Alves, J.F. Mano, Chitosan derivatives obtained by chemical modifications for biomedical and environmental applications, International J. Biological Macromolecules 43 (5) (2008) 401-414.

[3] T.C. Santos, A.P. Marques, S.S. Silva, J.M. Oliveira, J.F. Mano, A.G. Castro, R.L. Reis, In vitro evaluation of the behaviour of human polymorphonuclear neutrophils in direct contact with chitosan-based membranes, J. Biotechnology 132 (2) (2007) 218-226.

[4] M. Prabaharan, J.F. Mano, Chitosan-based particles as controlled drug delivery systems, Drug Delivery 12 (1) (2005) 41-57.

[5] K. Tuzlakoglu, C.M. Alves, J.F. Mano, R.L. Reis, Production and characterization of chitosan fibers and 3D fiber mesh scaffolds for tissue engineering applications, Macromolecular Bioscience 4 (8) (2004) 811-819.

[6] M. Prabaharan, M.A. Rodriguez-Perez, J.A. de Saja, J.F. Mano, Preparation and characterization of poly(L-lactic acid)-chitosan hybrid scaffolds with drug release capability, J. Biomedical Materials Research Part B: Applied Biomaterials 81B (2) (2007) 427-434.

[7] J. Shi, N.M. Alves, J.F. Mano, Chitosan coated alginate beads containing poly(Nisopropylacrylamide) for dual-stimuli-responsive drug release, J. Biomedical Materials Research Part B: Applied Biomaterials 84B (2) (2008) 595-603.

[8] E.B.O.R.M. Denkbas, Perspectives on: chitosan drug delivery systems based on their geometries, J. Bioactive Compatible Polymers 21 (2006) 351-368.

[9] H.M. Nie, L.Y. Lee, H. Tong, C.H. Wang, PLGA/chitosan composites from a combination of spray drying and supercritical fluid foaming techniques: new carriers for DNA delivery, J. Controlled Release 129 (3) (2008) 207-214.

[10] F.L. Mi, S.S. Shyu, Y.B. Wu, S.T. Lee, J.Y. Shyong, R.N. Huang, Fabrication and characterization of a sponge-like asymmetric chitosan membrane as a wound dressing, Biomaterials 22 (2) (2001) 165-173. 
[11] K. Oungbho, B.W. Muller, Chitosan sponges as sustained release drug carriers, International J. Pharmaceutics 156 (2) (1997) 229-237.

[12] D.W. Hutmacher, Scaffold design and fabrication technologies for engineering tissues-state of the art and future perspectives, J. Biomaterials Science: Polymer Edition 12 (2001) 107.

[13] O.R. Davies, A.L. Lewis, M.J. Whitaker, H. Tai, K.M. Shakesheff, S.M. Howdle, Applications of supercritical $\mathrm{CO}_{2}$ in the fabrication of polymer systems for drug delivery and tissue engineering, Advanced Drug Delivery Reviews 60 (3)(2008) 373-387.

[14] D.L. Tomasko, H.B. Li, D.H. Liu, X.M. Han, M.J. Wingert, L.J. Lee, K.W. Koelling, A review of $\mathrm{CO}_{2}$ applications in the processing of polymers, Industrial \& Engineering Chemistry Research 42 (25) (2003) 6431-6456.

[15] A.R.C. Duarte, J.F. Mano, R.L. Reis, Perspectives on: supercritical fluid technology for the preparation of 3D scaffolds for tissue engineering applications, J. Bioactive and Compatible Polymers 24 (2009) 385-400.

[16] I. Tsivintzelis, E. Pavlidou, C. Panayiotou, Porous scaffolds prepared by phase inversion using supercritical $\mathrm{CO}_{2}$ as antisolvent. I. Poly(L-lactic acid), J. Supercritical Fluids 40 (2007) 317.

[17] L. Tsivintzelis, S.I. Marras, L. Zuburtikudis, C. Panayiotou, Porous poly(L-lactic acid) nanocomposite scaffolds prepared by phase inversion using supercritical $\mathrm{CO}_{2}$ as antisolvent, Polymer 48 (2007) 6311.

[18] E. Reverchon, S. Cardea, E.S. Rappo, Production of loaded PMMA structures using the supercritical $\mathrm{CO}_{2}$ phase inversion process, J. Membrane Science 273 (2006) 97.

[19] Y.W. Kho, D.S. Kalika, B.L. Knutson, Precipitation of Nylon 6 membranes using compressed carbon dioxide, Polymer 42 (2001) 6119.

[20] H. Matsuyama, A. Yamamoto, H. Yano, T. Maki, M. Teramoto, K. Mishima, K. Matsuyama, Formation of porous flat membrane by phase separation with supercritical $\mathrm{CO}_{2}$, J. Membrane Science 194 (2001) 157.

[21] E. Reverchon, S. Cardea, Formation of cellulose acetate membranes using a supercritical fluid assisted process, J. Membrane Science 240 (2004) 187.

[22] H. Matsuyama, A. Yamamoto, H. Yano, T. Maki, M. Teramoto, K. Mishima, K. Matsuyama, Effect of organic solvents on membrane formation by phase separation with supercritical $\mathrm{CO}_{2}$, J. Membrane Science 204 (2002) 81.

[23] E. Reverchon, S. Cardea, Formation of polysulfone membranes by supercritical $\mathrm{CO}_{2}$, J. Supercritical Fluids 35 (2005) 140.

[24] M. Temtem, T. Casimiro, A. Aguiar-Ricardo, Solvent power and depressurization rate effects in the formation of polysulfone membranes with $\mathrm{CO}_{2}$-assisted phase inversion method, J. Membrane Science 283 (2006) 244

[25] M.S. Kim, S.J. Lee, Characteristics of porous polycarbonate membrane with polyethylene glycol in supercritical $\mathrm{CO}_{2}$ and effect of its porosity on tearing stress, J. Supercritical Fluids 31 (2004) 217.

[26] A.R.C. Duarte, J.F. Mano, R.L. Reis, Novel 3D scaffolds of chitosan-PLLA blends for tissue engineering applications: preparation and characterization, J. Supercritical Fluids (2010) 017, doi:10.1016/j.supflu.2010.05.

[27] M. Temtem, L.M.C. Silva, P.Z. Andrade, F. dos Santos, C.L. da Silva, J.M.S. Cabral, M.M. Abecasis, A.A. Aguiar-Ricardo, Supercritical $\mathrm{CO}_{2}$ generating chitosan devices with controlled morphology. Potential application for drug delivery and mesenchymal stem cell culture, J. Supercritical Fluids 48 (3) (2009) 269-277.

[28] E. Reverchon, R. Adami, S. Cardea, G.D. Porta, Supercritical fluids processing of polymers for pharmaceutical and medical applications, J. Supercritical Fluids 47 (2009) 484.
[29] M.Prabaharan, J.P. Borges, M.H. Godinho, J.F. Mano, Liquid crystalline behaviour of chitosan in formic, acetic, monochloroacetic acid solutions, Advanced Materials Forum III 514-516 (Pts 1 and 2) (2006) 1010.

[30] I.K. Shim, S.Y. Lee, Y.J. Park, M.C. Lee, S.H. Lee, J.Y. Lee, S.J. Lee, Homogeneous chitosan-PLGA composite fibrous scaffolds for tissue regeneration, J. Biomedical Materials Research Part A 84A (2008) 247.

[31] M.-J. Han, S.-T. Nam, Thermodynamic and rheological variation in polysulfone solution by PVP and its effect in the preparation of phase inversion membrane, J. Membrane Science 202 (1-2) (2002) 55.

[32] J.C. Giddings, M.N. Myers, L. Mclaren, R.A. Keller, High pressure gas chromatography of nonvolatile species, Science 162 (1968) 67.

[33] H.S. Byun, K. Kim, M.A. McHugh, Phase behavior modeling of supercritical carbon dioxide-organic acid mixtures, Industrial \& Engineering Chemistry Research 39 (2000) 4580.

[34] J.W. King, Z.Y. Zhang, Selective extraction of pesticides from lipid-containing matrixes using supercritical binary gas mixtures, Analytical Chemistry 70 (1998) 1431.

[35] O.S.P. Pfohl, G. Brunner, Usage of PE-a program to calculate phase equilibria, TU Hamburg-Harburg Hamburg, 1998.

[36] D.-Y. Peng, D.B. Robinson, A new two-constant equation of state 15 (1976) 59

[37] C.M. Hansen, Hansen Solubility Parameters, CRC Press, Boca Raton, Florida, 2000.

[38] Y. Marcus, The Properties of Solvents, John Wiley \& Sons, 1998.

[39] R. Ravindra, K.R. Krovvidi, A.A. Khan, Solubility parameter of chitin and chitosan, Carbohydrate Polymers 36 (1998) 121.

[40] H. Tompa, Polymer Solutions, Butterworths, London, 1956.

[41] P.J. Flory, Thermodynamics of high polymer solutions, J. Chemical Physics 9 (1941) 660.

[42] P. vandeWitte, P.J. Dijkstra, J.W.A. vandenBerg, J. Feijen, Phase separation processes in polymer solutions in relation to membrane formation, J. Membrane Science 117 (1996) 1.

[43] H. Matsuyama, M. Teramoto, R. Nakatani, T. Maki, Membrane formation via phase separation induced by penetration of nonsolvent from vapor phase. II. Membrane morphology, J. Applied Polymer Science 74 (1999) 171.

[44] H. Matsuyama, M. Teramoto, R. Nakatani, T. Maki, Membrane formation via phase separation induced by penetration of nonsolvent from vapor phase. I. Phase diagram and mass transfer process, J. Applied Polymer Science 74 (1999) 159.

[45] K. Kimmerle, H. Strathmann, Analysis of the structure-determining process of phase inversion membranes, Desalination 79 (1990) 283.

[46] A.J. Reuvers, J.W.A. Van Berg, C.A. Smolders, Formation of membranes by means of immersion precipitation. Part I. A model to describe mass transfer during immersion precipitation, J. Membrane Science 34 (1987) 45.

[47] A.J. Reuvers, C.A. Smolders, Formation of membranes by means of immersion precipitation. Part II. The mechanism of formation of membranes prepared from the system cellulose acetate-acetone-water, J. Membrane Science 34 (1987) 67.

[48] C.A. Smolders, A.J. Reuvers, R.M. Boom, I.M. Wienk, Microstructures in phaseinversion membranes. Part 1. Formation of macrovoids, J. Membrane Science 73 (1992) 259. 